\title{
Adaptation du virus de la peste des petits ruminants aux cultures cellulaires
}

Note préliminaire

\author{
por Y. GILBERT ef J. MONNIER
}

\section{INTRODUCTION}

L'affection dénommée «Peste des petits ruminants » (PPR) est due à un ultra-virus étroitement apparenté à celui de la peste bovine, avec lequel il possède une communauté antigénique étroite; les épreuves de séro-neutralisation croisées in vivo (1) et in vifro, et la prćcipitation en milieu gélifié, ne permettent pas de les distinguer: seul, leur pouvoir pathogène montre une différence marquée.

En effet, si le virus PPR provoque chez les caprins et les ovins l'évolution d'une affection dans laquelle les symptômes observés sont très semblables à ceux que présentent les bovins infectés par le virus de la peste bovine classique (hyperthermie, état typhique, ulcération de la muqueuse buccale, diarrhée profuse et mort) ce même virus injecté à des bovins des races les plus sensibles à la peste bovine ne provoque qu'une légère hyperthermie suivie de l'apparition de la résistance au virus $P B$.

La PPR a été signalée d'abord au Dahomey. en Côte d'Ivoire et, plus récemment, au Sénégal où elle entraîne des pertes sensibles dans les effectifs de petits ruminants.

Aucun vaccin n'est jusqu'ici disponible, sauf le vaccin bovipestique lapinisé qui auraił donné de bons résultats en Côte d'Ivoire: mais ses difficultés de production et son prix de revient élevé en interdisent un emploi extensif.

C'est pourquoi il a semblé intéressant de tenter l'adaptation de ce virus aux cultures cellulaires, dans l'espoir que des passages en série en atténueraient le pouvoir pathogène et permettraient la production d'un vaccin efficace.

Rev. Elev. Méd. vét. Pays trop. 1962, 15, no 4.

Reçu pour publication : août 1962.
Le présent article rapporte les premiers résultats obtenus.

\section{MATÉRIEL ET MÉTHODES}

Préparation des suspensions cellulaires.

Toutes les expériences ont été réalisées à l'aide de cellules épithéliales de reins d'embryons ovins en provenance de l'abattoir de Dakar.

L'âge des embryons n'a pas été pris en considération.

Les reins sont décapsulés, la zone corticale prélevée en petits fragments à l'aide d'un bistouri ; ces fragments sont hachés, lavés 3 fois au PBS*, soumis à l'action d'une solution de trypsine Difco $(1: 250)$ à 3 p. 1.000 pendant 20 minutes à la température du laboratoire, sur agitateur magnétique. La trypsine est éliminée par décantation ef remplacée par une solution fraîche de trypsine. La trypsination est pourșuivie pendant 5 d̀ 6 heures au réfrigérateur. Au bout de ce temps, la suspension cellulaire est filtrée sur gaze (4 épaisseurs), centrifugée à 900 tours/minute, pendant 4 à 5 minutes. Le surnageant est éliminé et le culot cellutaire lavé avec de la solution saline de Hanks additionnée de 10 p. 100 de sérum bovin. Après centrifugation, le culot cellulaire est mis en suspension à raison de 1 volume pour 300 de milieu nutritif composé de solution de Hanks additionnée de 0,5 p. 100 d'hydrolysat de lactalbumine, et 0.1 p. 100 d'extrait de levure, auquel on ajoute 10 p. 100 de sérum de veau (importé de France) ainsi que des antibiotiques: Pénicilline, $100 \mathrm{Ul} / \mathrm{ml}$ et Streptomycine, $0,1 \mathrm{mg}$ par $\mathrm{ml}$.

Les renouvellements ultérieurs de milieu sont

* P B S : Phosphate buffer solution (Solution Dulbecco). 
effectués tous les 2 ou 3 jours à l'aide du même milieu, mais la proportion de sérum est ramenée à 5 p. 100 de sérum de bovin (importé de France) au 1 er changement, et à 2 p. 100 pour les changements ultérieurs, qui s'effectuent lorsque le virage de l'indicateur coloré indique un $\mathrm{pH}$ nettement acide.

\section{Récipients pour culture.}

La suspension cellulaire est répartie soit en tubes de verre neutre ou de Pyrex de $18 \times 180$ à la dose de $2 \mathrm{ml}$, soit en tubes de Leighton à la même dose, soit en flacons plats pharmacie de $150 \mathrm{ml}$, à la dose de $1 \mathrm{~b} \mathrm{ml}$, soit en tlacons de $250 \mathrm{ml}$ en verre neutre à la dose de $22,5 \mathrm{ml}$.

Pour la production de grandes quantités de virus, on utilise des boîtes de Roux de 1 I recevant $75 \mathrm{ml}$ de suspension cellulaire.

\section{Incubation.}

Les flacons et tubes sont placés, après répartition de la suspension, en position stationnaire pendant 2 à 3 jours.

Le milieu est alors renouvelé.

Les flacons demeurent immobiles, alors que les tubes sont placés sur un tambour tournant (système roller-fubes).

La température d'incubation est, selon les cas, de $37^{\circ}$ ou $40^{\circ} \mathrm{C}$.

\section{Souches de virus.}

Des virus de différentes provenances ont été utilisés pour tenter d'infecter des cultures cellulaires. Seule a été couronnée de succès l'infection de couches monocellulaires par le sang provenant d'un mouton de race maure, spontanément infecté de PPR.

Ce mouton, amené malade au laboratoire, présentait une température de 4104 et des ulcérations de la muqueuse buccale et pharyngée.

Un prélèvement de sang fut pratiqué par ponction veineuse immédiatement avant l'abattage, puis, après celui-ci, la rate et des ganglions furent prélevés. Le sang obtenu fut aussitôt défibriné par agitation dans un ballon contenant des billes de verre.

\section{Passage du virus.}

a) Promicr passage.

Rate et ganglions sont broyés séparément au mortier en présence de poudre de verre, puis des suspensions à 10 p. 100 de ces tissus sont préparées dans de la solution de Hanks, et centrifugées à $2.000 \mathrm{t} /$ minute pendant 10 minutes.

Dans des tubes contenant des cellules de rein d'embryon de mouton mises en culture quatre jours auparavant, on introduit $2 \mathrm{ml}$ de suspension de rate ou de ganglion, ou de sang défibriné.

Après 24 heures d'incubation à $370 \mathrm{C}$, le liquide infectant est remplacé par du milieu nutritif de Hanks, après rinçage des cellules au PBS.

b) Passages ultérieurs.

Ils sont effectués en ajoutant du milieu du passage précédent à une suspension cellulaire frầchement préparée, ou au milieu de renouvellement de couches cellulaires déjà constituées.

\section{Titrage du virus.}

En vue des titrages, le virus est dilué en série décimale dans du liquide de Hanks (dilutions $10^{-1}$ à $10^{-6}$ ).

On porte alors $1 \mathrm{ml}$ de chacune des dilutions dans un tube contenant $10 \mathrm{ml}$ de suspension cellulaire. Après le mélange, le contenu de chaque tube de suspension infectée est réparti à la dose de $2 \mathrm{ml}$ dans 5 tubes en verre neutre ou Pyrex de $18 \times 180$.

Chaque tube reçoit donc $0,2 \mathrm{ml}$ de la dilution considérée.

Pour les titrages plus précis, on recourt à 10 tubes par dilution.

\section{Identification du virus par séroneutralisation.}

Le virus à identifier est dilué en une série de dilutions décimales $10^{-1}$ à $10^{-6}$.

Deux séries de' 6 tubes sont préparées.

Chaque série reçoit $1 \mathrm{ml}$ des différentes dilutions de virus.

A chacun des tubes d'une série on ajoute $1 \mathrm{ml}$ de sérum antibovipestique préparé soit sur lapin, soit sur bœuf.

Les tubes de l'autre série reçoivent $1 \mathrm{ml}$ de sérum de bovin réceptif. 
Après agitation, les fubes sont mis en incubation $1 \mathrm{~h}$ au bain-marie.

Les différents mélanges sont répartis à la dose de $0,2 \mathrm{ml}$ par tube contenant $2 \mathrm{ml}$ de suspension cellulaire.

On utilise 2 à 5 tubes par mélange.

Le virus est considéré comme neutralisé s'il existe une différence d'au moins 2 log à base 10 entre les titres des virus respectivement en présence de sérum normal et de sérum antibovipestique.

\section{Préparations colorées.}

Elles sont réalisées à l'aide de tubes de Leighton recevant $2 \mathrm{ml}$ de suspension cellulaire, infectée ou non.

Pour la coloration, les tubes sont vidés, lavés 3 fois au PBS, la couche cellulaire est fixée 3 à 5 minutes au Bouin alcoolique, puis colorée par I'hémalun de Mayer ef l'éosine. Montage au baume du Canada.

\section{Inoculation aux animaux.}

Bovins. - Sont utilisés des bovins sans bosse de race N'Dama, provenant de la région de Kédougou, très sensibles à la peste bovine. Avant toute inoculation un prélèvement de sang est effectué, ef le sérum soumis à une épreuve de séroneutralisation, en culture cellulaire à la dilution $1: 2$. Seuls, sont retenus pour les expériences, les bovins dont le sćrum apparait complètement dépourvu d'anticorps neutralisant le virus bovipestique en culture cellulaire (présence d'effet cytopathogène dans les quatre tubes inoculés avec le mélange sérum-virus de culture).

Caprins. - Sont utilisés des caprins âgés de 6 à 12 mois provenant de la région de Fatick (Sénégal) de Thiès, ou de Kédougou. Le sérum de ces caprins est examiné avant toute inoculation pour détection des anticorps neutralisant le virus bovipestique de culture.

Quinze jours après inoculation de virus PPR ef avant toute épreuve, les animaux survivants (bovins ou caprins) subissent un second prélèvement de sang en vue d'obtenir du sérum (sérum B).

\section{RÉSULTATS}

Premier passage du virus sur cultures cellulaires.

Suspension ganglionnaire.

Après 24 heures à l'éfuve à $370^{\circ} \mathrm{C}$, les cellules sont complètement détruites (effet toxique de l'inoculum) et les tubes sont éliminés.

Suspension de rate.

Après 24 heures à l'étuve à $37^{\circ} \mathrm{C}$, un effet toxique limité est observé sur la couche cellulaire ; cependant la majorifé des cellules demeure intacte.

Aucun effet cytopathogène n'apparaît en 11 jours et, le tapis cellulaire étant décollé, les tubes sont éliminés.

Un deuxième passage est effectué, puis un troisième, mais aucun effet cytopathogène ne se manifeste pendant la période d'observation. Les passages sont abandonnés à l'issue du quatrième.

Sang.

Après 24 heures à l'éłuve à $370 \mathrm{C}$, les cellules, après lavage au PBS, apparaissent intactes. Le milieu est régulièrement renouvelé.

Dix jours après l'infection, de larges plaques ressemblant à des cellules géantes se forment au sein de la couche cellulaire. Ces plaques augmentent en taille et en nombre, et se creusent d'énormes vacuoles.

Ces lésions persistent pendant plus de 21 jours. délai au bout duquel les tubes sont éliminés.

Dès le $2^{e}$ passage, un test d'identification par séro-neutralisation indique que l'effet cytopathogène est totalement inhibé par le sérum d'un bouc guéri de PPR et par le sérum antibovipestique.

A partir du virus obtenu par premier isolement en culture, récolté à plusieurs reprises entre le $11 \mathrm{e}$ et le $21 \mathrm{e}$ jour après l'infection, deux séries de passages ont été commencées, l'une à la température de $370^{\circ}$, l'autre à $40^{\circ} \mathrm{C}$.

\section{Passages à $40^{\circ} \mathrm{C}$.}

Le milieu nutritif baignant les cellules infectées du 1 er isolement du virus est mélangé à une suspension cellulaire de rein d'embryon de mouton lors de la mise en culture. Un effet cytopathogène est observé 9 jours plus tard; il se traduit par l'apparition au sein du tapis cellulaire, de 
arges plaques constituées par d'énormes cellules géantes.

Au cours des passages suivants l'effet cytopathogène peut être décelé par observation à l'état frais dès le $5 e$ jour ; il se traduit toujours par l'apparition de syncytiums. Il n'existe pas de cellules rondes réfringentes isolées ou groupées en chaînes, comme on en observe dans les cultures infectées par le virus bovipestique.

Dans une deuxième série de six passages effectuée dans les mêmes conditions, à partir du virus de 1er isolement, par passages successifs en suspension cellulaire fraîche, l'effet cytopathogène se manifeste régulièrement après 7 jours d'incubation.

Après apparition des premiers syncytiums, ceux-ci s'accroissent en taille et en nombre, et bientôt la culture est constituée par des cellules géantes, séparées par des cordons de cellules de type fibroblastique. Cet aspect persiste très longtemps, et une couche cellulaire presque continue est visible à l'œil nu sur des flacons ensemencés 36 jours plus tôt.

\section{Passages à $37^{\circ} \mathrm{C}$.}

Une série de 12 passages en série a été réalisée.

Le milieu du précédent passage est incorporé à la suspension cellulaire lors de sa mise en culture, sauf au $2^{\mathrm{e}}$ passage effectué par infection 2 jours après leur mise en culture de cellules de rein d'embryon de 'mouton à l'aide du milieu nutritif de tubes du 1 er passage, et au $5^{e}$ passage effectué sur des cellules de 5 jours. L'effet cytopathogène apparaît en 6 à 7 jours, se manifestant par des zones d'apparence unie, renfermant de nombreux points réfringents qui sont les nucléoles des noyaux des syncytiums. Comme les cellules de rein d'embryon de mouton donnent des cultures extrêmement: denses et qu'il n'est pas rare d'observer des zones où les cellules forment plusieurs couches, les lésions dues à l'infection sont parfois difficiles à identifier. En 12 à 14 jours, toute la surface du verre semble couverte de syncytiums sans tendance marquée à la vacuolisation. Ces cellules géantes subsistent pendant un temps très long (plus de 3 jours), elles présentent une partie centrale réfringente, opaque et jaunâtre, bordée par les noyaux disposés en une couronne entourée d'une zone périphérique plus claire.
Caractéristiques microscopiques des lésions déterminées par le virus sur les cellules cultivées in vitro.

10 Dans des couches cellulaires obtenues par infection de suspensions lors de la mise en culture des cellules, incubées à $370 \mathrm{C}$.

En raison de la rapidité de croissance des cellules de mouton el de la lenteur d'apparition de I'E. C. P. (effet cytopathogène) celui-cli ne commence en général à se manifester qu'au sein d'une couche cellulaire entièrement constituée.

Au 5 e jour, les premiers effets cytopathogènes se traduisent par l'apparition d'amas de 2 à 6 noyaux, constituant l'amorce de cellules géantes, au milieu d'une zone de cytoplasme clair. Souvent, ces noyaux contiennent des inclusions sous forme d'une à 4 taches circulaires incolores, centrées par un point fortement éosinophile. Le nucléole est loujours infuct. Pur ailleurs, des inclusions de ce type se rencontrent dans les noyaux de cellules encore individualisées. Ces cellules sont en général groupées par zones bien déterminées.

Au 7 e jour, on observe des groupes de plusieurs petites cellules multinucléées, dont les noyaux renferment de 1 à 6 inclusions rose vif entourées d'un halo clair. De même, nombreuses sont les cellules isolées possédant de telles inclusions, dont la taille tend à augmenter. La tache éosinophile centrale est circulaire ou de forme allongéc.

Au 8 e jour, les inclusions sont encore plus nombreuses, et occupent la plus grande part de la surface du noyau.

A partir du ge jour se constituent. par fusion d'éléments multinucléés voisins, de grands syncytiums, dont les noyaux se disposent en couronne, autour d'une zone centrale circulaire ou ovoïde fortement éosinophile. Les noyaux de ces cellules contiennent ou non des inclusions dont certaines occupent la quasi-totalité du noyau. En ce qui concerne le reste de la couche cellulaire, les limites des cellules deviennent difficiles à distinguer, d'autant plus que la culture est en général très dense. Le cytoplasme renferme des masses éosinophiles, et la plupart des noyaux, des inclusions.

Au 13 e jour, presque toutes las cellulcs sont infectées. Les cellules géantes ont atteint des proportions étendues. Les inclusions intranucléaires 
occupent toute la surface du noyau, à l'exception d'un liseré périphérique. La tache rose centrale est plus ou moins étendue. Les plus petites sont intensément colorées alors que d'autres de plus grande dimension présentent une coloration plus pâle.

Au $17 \mathbf{e}$ jour, l'image est à peu près la même, mais la culture devient moins dense par suite de la dégénérescence et du détachement de quelques cellules.

La durée maxima de survie des cultures infectées n'a pas encore été déterminée.

$2^{\circ}$ Dons les couches cellulaires obtenues por infection de suspension cellulaire lors de la mise en culture, des cellules incubées d $40^{\circ} \mathrm{C}$.

L'effet cytopathogène observé dans ces condiditions est analogue à celui qui se manifeste à $370 \mathrm{C}$, mais l'évolution en est plus rapide.

Dès le $4 \mathrm{e}$ jour, se constituent de petits amas de quelques noyaux. Les inclusions intracellulaires, petites, claires et centrées par un point rouge ne se voient qu'au 5 e jour.

Au $6^{e}$ jour, de nombreuses cellules géantes sont déjà constituées, dont les noyaux, disposés en couronne, renferment des inclusions rose vif entourées d'un halo. Ces inclusions ont une taille très sensiblement supérieure à celle des inclusions observées en même temps à $37^{\circ} \mathrm{C}$.

Au 7 e jour, ces cellules multinucléées occupent une part appréciable de la surface de la culture: $1 / 4$ à $1 / 5$ environ. Les noyaux sont disposés en couronne autour d'un centre intensément coloré, la taille de ces cellules varie, elles peuvent contenir de quelques noyaux à plusieurs centaines. Pratiquement tous les noyaux, tant dans les syncytiums que dans les autres cellules, renferment des inclusions, à part quelques petites zones éparses qui renferment des cellules apparemment normales.

Après le $10^{\mathbf{e}}$ jour, un certain nombre ce cellules se détachent et la culture cpparaît moins dense. Les inclusions nucléaires s'ooservent dans tous les noyaux. Certaines cellules géantes présentent des signes de dégénérescence : les noyaux semblent se rétracter, montrent des formes irrégulièrement polygonales, la bordure chromatique perd de sa netteté et le reste du noyau prend une coloration violacée. pâle à l'intérieur et à l'extérieur de la couronne de noyaux.

Dans les autres cellules, les inclusions nucléaires se présentent surtout sous la forme d'une tache rose vif bien délimitée, entourée d'un halo clair, lui-même bordé d'un liseré chromatique assez mince.

Dans d'autres, la tache rose s'étend et sa couleur perd de l'intensité et sa limite avec le halo devient indistincte. Enfin, d'autres noyaux montrent un centre rose pâle homogène, bordé d'un liseré chromatique.

Dans cet état, la culture persiste pendant plusieurs semaines. Un flacon coloré 36 jours après la mise en culture présentait une couche cellulaire encore visible à l'œil nu.

Après coloration on pouvait distinguer de nombreux syncytiums de grande taille, au cytoplasme vacuolé. L'examen au fort grossissement ne put être eflectué en raison de l'épaisseur du verre.

\section{Titre et croissance du virus.}

Les titrages ont essentiellement été effectués avec la souche maintenue à $40^{\circ} \mathrm{C}$ dont il était intéressant de connaître le titre pour des raisons exposées plus loin.

Le tableau suivant rassemble des chiffres enregistrés :

\begin{tabular}{|c|c|c|c|}
\hline Sérje & $\begin{array}{c}\text { No } \\
\text { du passage }\end{array}$ & $\begin{array}{l}\text { Jour du pré- } \\
\text { lèvement } \\
\text { après mise } \\
\text { en culture }\end{array}$ & $\begin{array}{l}\text { titre par } \mathrm{cm}^{3} \\
\text { (nombre de } \\
\text { DI/CT) }\end{array}$ \\
\hline 1 & $4 e$ & $8^{e}$ & $10^{5,2}$ \\
\hline 1 & $6 e$ & $5^{e}$ & $10^{4,2}$ \\
\hline 1 & $6 e$ & $12^{e}$ & $10^{5,3}$ \\
\hline 1 & $6^{e}$ & $14^{e}$ & $10^{5,2}$ \\
\hline 2 & $3 e$ & $11 \mathrm{e}$ & $10^{5,2}$ \\
\hline 3 & $3 e$ & $13^{e}$ & $10^{4}, 8$ \\
\hline
\end{tabular}

Une courbe de croissance a été établie pour le virus du $4 \mathrm{e}$ passage incubé à $40^{\circ} \mathrm{C}$.

Au 1er titrage, effectué 4 jours après infection Le cytoplasme devient vacuolaire, lâche et I lors de la mise en culture, le milieu nutritif con- 


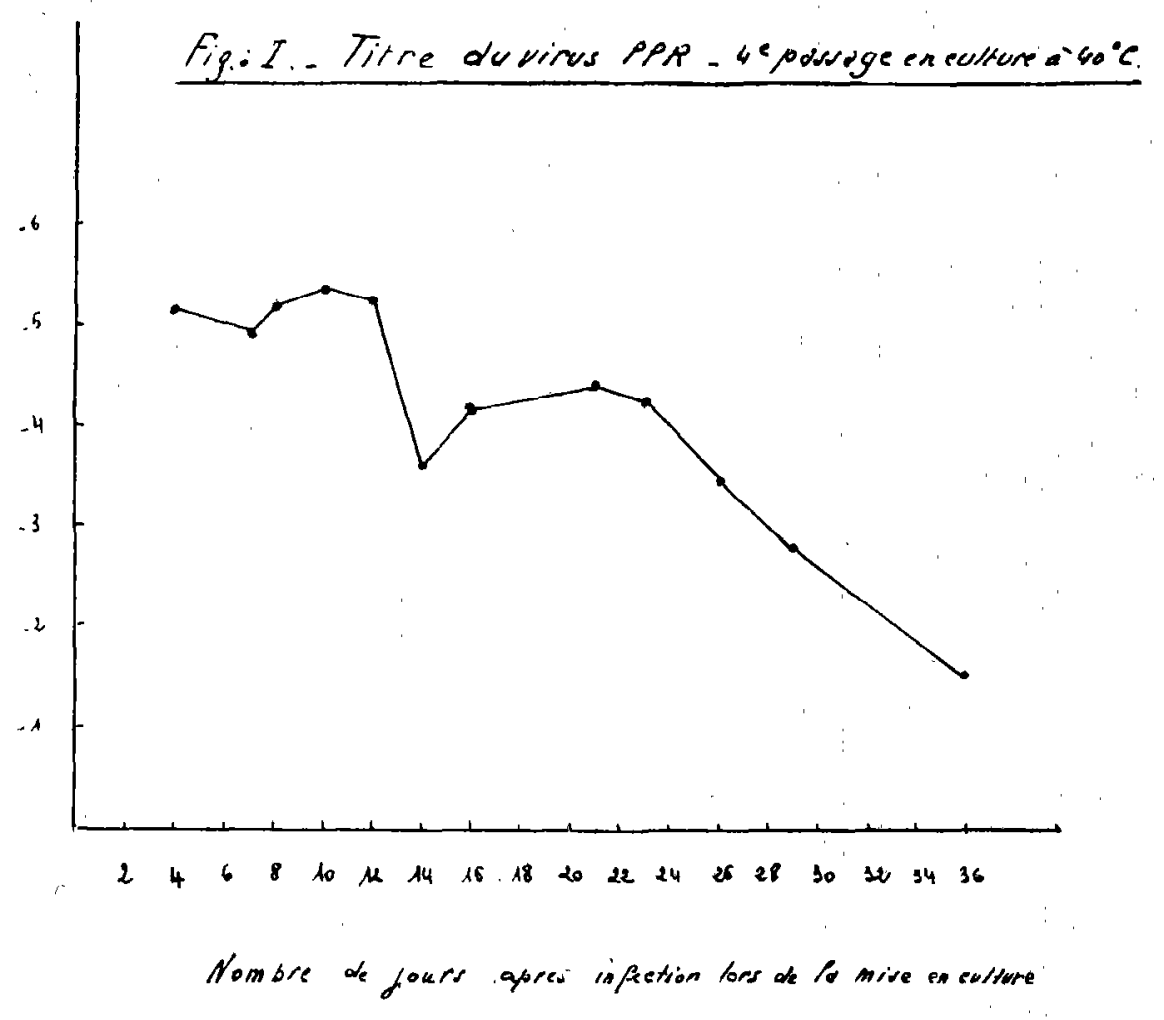

tient déjà $10^{5,1}$ doses infectantes pour culture cellulaire (DICT) par $\mathrm{ml}$. Le maximum est atteint au $10^{\mathrm{e}}$ jour de culture, avec $10^{5,3}$ DICT par ml.

Le titre baisse vers le $14 \mathrm{e}$ jour et se stabilise du $16^{\mathrm{e}}$ au $25^{\mathrm{e}}$ jour aux environs de $10^{4} \mathrm{DICT}$ par $\mathrm{ml}$.

Le titre baisse alors sensiblement pour atteindre au $35^{\mathrm{e}}$ jour après la mise en culture un titre de 101,4 DICT par $\mathrm{ml}$.

L'expérience a été interrompue alors que les flacons présentaient encore une couche cellulaire discernable formée de syncytiums et de traînées de cellules de type fibroblastique.

Un seul titrage de la souche entretenue à $37^{\circ} \mathrm{C}$ a été effectué àu $12^{\mathrm{e}}$ passage.

Le milieu prélevé au 10 e jour de culture contient 105,1 DICT par m!.

Pouvoir pathogène des souches PPR de culture.

\section{Io Souche entretenue à $370 \mathrm{C}$.}

Pouvoir pathogène pour les caprins.

Le virus de 1 er passage de culture cellulaire inoculé à deux caprins dont le sérum ne neutra- lisait pas le virus bovipestique en culture cellulaire provoque, après une incubation de 3 et 5 jours respectivement, une élévation thermique de $2^{\circ} \mathrm{C}$. Au 8 e jour, la face interne des lèvres et des joues sont couvertes d'un enduit nécrotique. La diarrhée apparaît le 8 e jour. La température descend brusquement et redevient normale le $10 \mathrm{e}$ jour tandis que les lésions buccales disparaissent. Les deux boucs survivent.

Avec le virus du $6^{e}$ passage, l'un des deux boucs inoculés ne présente qu'une réaction thermique très faible (moins de $1^{\circ} \mathrm{C}$ ) et survit jusqu'au $21 \mathrm{e}$ jour après l'infection. A l'autopsie, seules sont relevées des lésions de pneumonic. Le sérum prélevé au 16e jour après infection neutralise le virus bovipestique de culture à la dilution $1 / 100$.

Le second bouc montre une réaction thermique intense du $5^{\mathrm{e}}$ au $11 \mathrm{e}$ jour après inoculation. II meurt le $17 \mathrm{e}$ jour mais ne présente aucun signe de PPR à l'autopsie.

$A \cup 12^{e}$ passage, le virus inoculé à deux boucs réceptifs ne provoque qu'une réaction thermique fugace ( 2 jours au maximum) et n'excédant pas $10 \mathrm{C}$. Les deux animaux survivent. 


\section{$2^{\circ}$ Souche entrefenue à $40^{\circ} \mathrm{C}$.}

a) Pouvoir pothogènc pour les caprins.

Au 3 e passage à $40^{\circ} \mathrm{C}, 4$ jeunes boucs sont inoculés. La maladie évolue chez eux de façon similaire : après une incubation de 3 jours la température s'élève brusquement, atteint et dépasse même $41^{\circ} \mathrm{C}$ au matin du $5^{e}$ jour. Les lésions de la muqueuse buccale apparaissent du 6e jour au 7 e jour suivant l'inoculation. et is mort survient du $6^{\mathrm{e}}$ au $9 \mathrm{e}$ jour.

A l'autopsie, les lésions caractéristiques sont observées : nécrose de la face interne des levres, de la face inférieure de la langue, de la muqueuse du pharynx, congestion de la valvule iléo-crecale. b) Titrage du virus sur coprins.

Le virus du 3 e passage est titré sur des lots de 4 jeunes boucs.

Les résultats observés sont groupés dans le tableau I.

Ainsi le virus PPR en culture infecte les caprins à la dose de $1 \mathrm{ml}$ de la dilution $10^{-5}$. Ce titre est analogue à celui calculé sur cultures cellulaires $\left(10^{5,2} \mathrm{DICT}\right.$ par $\left.\mathrm{ml}\right)$.

\section{Pouvoir pathogène ef immunogène pour les bovins.}

Seule a été inoculée aux bovins la souche entretenuc par passage à $10^{\circ} \mathrm{C}$.

TABIEAU I

Titrage du vinus PPR sur cyorins (3ème passage à $40^{\circ} \mathrm{C}$ )

\begin{tabular}{|c|c|c|c|c|c|c|c|c|}
\hline \multirow{2}{*}{$\begin{array}{l}\text { Dilution } \\
\text { di vimis }\end{array}$} & \multirow{2}{*}{$\begin{array}{l}\text { :0 des } \\
\text { boucs }\end{array}$} & \multirow{2}{*}{$\begin{array}{l}\text { Réaction } \\
\text { therminie }\end{array}$} & \multirow{2}{*}{$\begin{array}{l}\text { Lésions } \\
\text { bucçles }\end{array}$} & \multirow{2}{*}{$\begin{array}{l}\text { Mort=ly } \\
\text { ou } \\
\text { Suries }\end{array}$} & \multicolumn{2}{|c|}{$\begin{array}{l}\text { inticorps neutralisants } \\
\text { dans le sérum }\end{array}$} & \multirow{2}{*}{$\begin{array}{l}\text { Lésions à } \\
\text { I'autopsie }\end{array}$} & \multirow[t]{2}{*}{ : } \\
\hline & & & & & $\begin{array}{c}\text { Avant } \\
\text { iroculation }\end{array}$ & $\begin{array}{l}15 \text { joaprès } \\
\text { inoculation }\end{array}$ & & \\
\hline \multirow[t]{2}{*}{$10^{-2}$} & 43 & 0 & 0 & $s$ & + & + & - & \\
\hline & 49 & \pm & 0 & $S$ & 0 & + & - & \\
\hline \multirow[t]{4}{*}{$10^{-3}$} & 45 & + & + & K gè j. & 0 & - & + & \\
\hline & 50 & + & + & M 7è j. & 0 & - & + & \\
\hline & 51 & + & + & M 7è j. & 0 & - & + & . \\
\hline & 23 & 0 & 0 & li 5 è j. & 0 & - & 0 & mort de pneu- \\
\hline \multirow[t]{4}{*}{$10^{-4}$} & 46 & + & + & $\because 10 \doteq \div$ & 0 & - & + & \\
\hline & $\therefore \varepsilon$ & + & 0 & $s$ & 0 & + & - & \\
\hline & 35 & + & 0 & $\because 6 \grave{\text { è }}$ & 0 & - & 0 & $\begin{array}{l}\text { congestion } \\
\text { pulmonaire }\end{array}$ \\
\hline & 20 & + & $\dot{-}$ & Y $11 \grave{e}$ & 0 & - & + & \\
\hline \multirow[t]{4}{*}{$10^{-5}$} & 39 & + & + & $\because 10 \hat{\vdots}=$ & 0 & - & + & \\
\hline & 44 & \pm & 0 & $\because \because$ i & 0 & - & + & \\
\hline & 53 & + & + & $\because$ & c & - & + & \\
\hline & 38 & + & $I$ & $\mathrm{~S}$ & 0 & + & - & \\
\hline \multirow[t]{2}{*}{$10-6$} & 22 & 0 & 0 & $\because$ & $G$ & - & 0 & $\begin{array}{l}\text { mort de pneu- } \\
\text { monie. }\end{array}$ \\
\hline & 40 & 0 & 0 & 5 & + & + & - & \\
\hline
\end{tabular}


Au $3^{\mathrm{e}}$ passage, un veau reçoit $2 \mathrm{~m}$ l de milieu, soit environ 300.000 DICT par voie sous-cutanée. II ne présente dans les jours suivants qu'une élévation thermique de $1^{\circ} \mathrm{C}$ environ les $5^{\mathrm{e}}$ et $6 \mathrm{e}$ jours sans aucun, signe clinique. Son sérum, dépourvu avant inoculation d'anticorps neutralisant le virus $\mathrm{PB}$, le neutralise 14 jours plus tard à la dilution 1/25. Cet animal demeure indifférent à l'inoculation de $100.000 \mathrm{DL}_{50}$ de virus bovipestique caprinisé pratiquée 35 jours après inoculation de virus PPR.

Deux boucs placés au contact de cet animal durant toute la durée de l'expérience ne montrent aucun trouble et succombent à l'inoculalion de virus PPR pratiquée le même jour que l'épreuve par virus caprinisé chez les bovins.
Le virus PPR ne semble donc pas se propager du bovin infecté au bouc sensible par cohabitation.

L'épreuve d'innocuité étant concluante, du virus du $3 \mathrm{e}$ passage a été titré comparativement sur boucs, cellules et veaux.

Le virus, ainsi qu'il a été signalé plus haut, renfermait $10^{5,2}$ DICT par $\mathrm{ml}$ et infectait 4 boucs sur 4 à la dose de $1 \mathrm{ml}$ d'une dilution $10^{-5}$.

Des 5 bovins de race N'dama recevant chacun $1 \mathrm{ml}$ d'une dilution $10^{-4}$ de virus, deux meurent avant l'épreuve d'affections intercurrentes (parasitisme et misère physiologique) et le troisième possède dans son sérum prélevé avant inoculation de virus. PPR, des anticorps neutralisant le virus PB. Seuls, les deux autres veaux doivent donc être pris en considération.

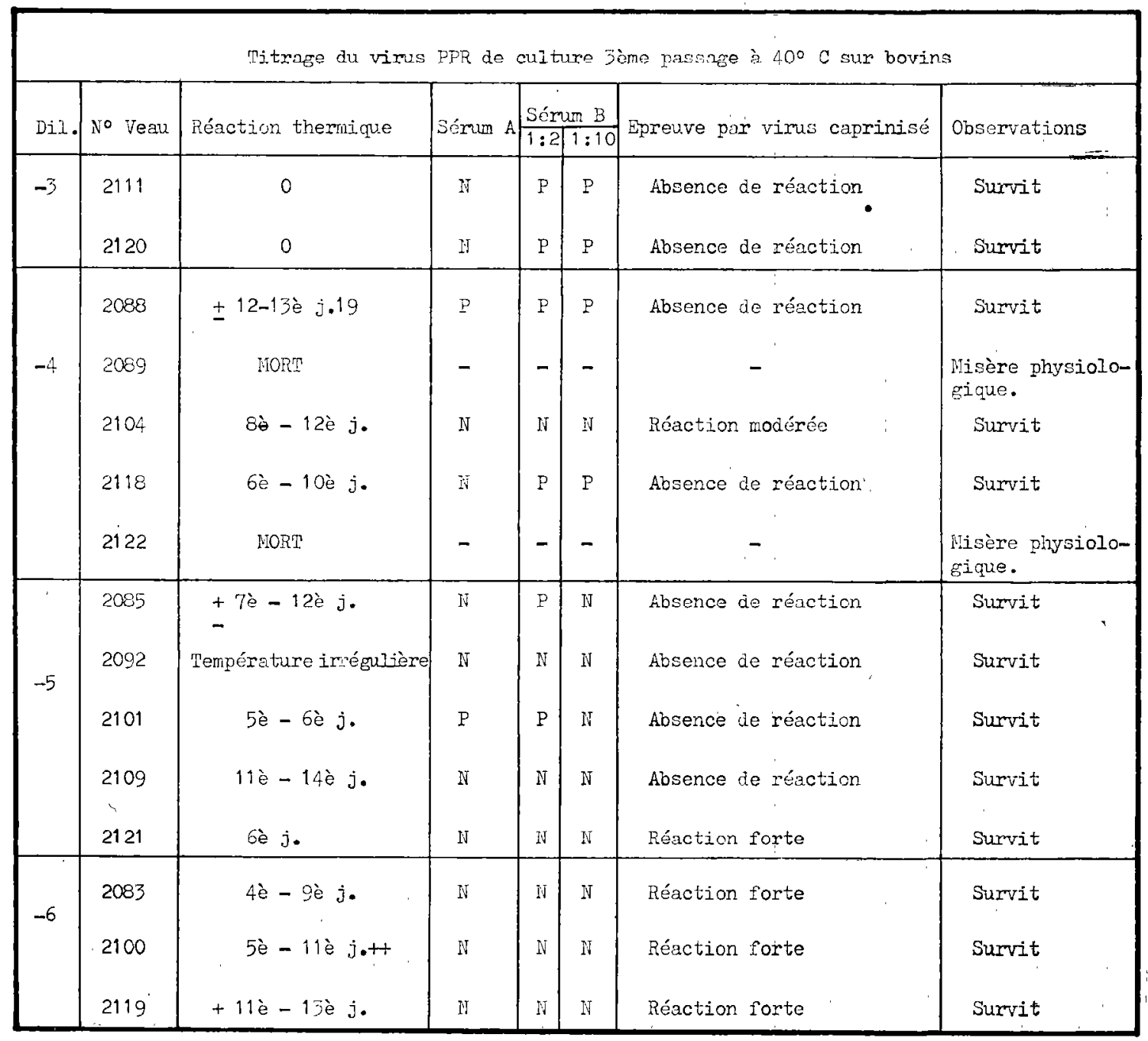


L'un deux possède dans son sérum prélevé 15 jours après inoculation du virus PPR, des anticorps neutralisant le virus $\mathrm{PB}$ et ne réagit pas d̀ l'épreuve par virus bovipestique caprinisé.

Le second, dont le sérum se révèle dépourvu d'anticorps neutralisant le virus PB 15 jours après l'inoculation du virus $P P R$, réagit faiblement à l'inoculation d'épreuve de virus bovipestique caprinisé.

Des 5 veaux recevant le virus PPR à la dilution $10^{-5}$, quatre possèdent avant l'expérience un sérum dépourvu d'anticorps neutralisant le virus $P B$. De ceux-ci, un seul renferme dans son sérum, quinze jours après inoculation du virus $P P R$, des anticorps neutralisant le virus $P B$ à un taux faible (1/2) et ne réagit pas à l'épreuve. Des trois animaux au sérum dépourvu d'anticorps neutralisonts, deux ne présentent aucune réaction thermique à l'inoculation d'épreuve, alors que le troisième réagit fortement.

Une nette réaction thermique est enregistrée après épreuve par virus bovipestique caprinisé chez les trois bovins inoculés avec $1 \mathrm{ml}$ de la dilution $10^{-6}$ de virus PPR.

\section{DISCUSSION}

Plusieurs tentatives d'adaptation du virus PPR sur cultures cellulaires avaient abouti à des échecs; I'infection des cultures de cellules épithéliales de rein de mouton, était tentée à l'aide de suspensions de rate ou de ganglions. Le procédé ne semble pas convenable, puisqu'il a échoué avec les suspensions d'organes de l'animal dont le sang au contraire a permis l'adaptation du virus aux cultures.

II est inhabituel de constater la PPR chez les petits ruminants des zones sahéliennes, et encore plus chez les ovins de ces régions.

L'origine de la contamination du moutonsouche n'a pu être élucidée. Il s'agit là d'un heureux hasard, et les circonstances ont permis de l'exploiter.

Deux séries de passages, à différentes :empèratures, ont été effectuées.

De la série à $370 \mathrm{C}$, est attendue l'atténuation de la souche pour les petits ruminants, dans l'espoir d'obtenir un vaccin efficace. Les seules expériences effectuées consistent en l'inoculation de boucs pour recherche du pouvoir pathogène et de son atténuation éventuelle. Malheu- reusement, des incidents, et, en particulier, des contaminations microbiennes, ont obligé à des retours en arrière si bien que la souche n'a jusqu'ici atteint que le $12^{\mathrm{e}}$ passage.

Par incubation à $40^{\circ} \mathrm{C}$ est envisagé le maintien du pouvoir pathogène pour les petits ruminants, et du pouvoir immunogène pour le bœuf, afin de disposer éventuellement d'une souche vaccinale contre la peste bovine.

II n'était donc pas souhaitable de multiplier les passages en culture à $40^{\circ} \mathrm{C}$, le virus PPR étant de lui-même suffisamment atténué pour les bovins au point d'être toléré par les races les plus sensibles. C'est pourquoi la majorité des expériences ont été consacrées à la souche maintenue à $40^{\circ} \mathrm{C}$ (titrages en culture, sur caprins ef bovins).

A partir de l'isolement du virus en culture, les deux séries de passages ont été poursuivies sans difficulté. L'effet cytopathogène est nettement discernable à l'état frais à partir du $6^{\circ}$ ou $7 \mathrm{e}$ jour, et son délai d'apparition ne se raccourcit pas malgré la répétition des passages.

Cette durée de latence des lésions cellulaires est nettement supérieure à celle observée dans la peste bovine, et, à l'état frais, l'aspect des lésions est sensiblement différent. On ne note pas ces cellules arrondies, réfringentes, filamenteuses par lesquels débutent les foyers d'infection des cultures infectées par le virus bovipestique, mais seulement des zones arrondies ou ovalaires, constituées de grandes cellules multinucléées, au sein du tapis qui a eu le lemps de se constituer complètement, compte tenu de la rapidité plus grande de «couverture» du verre par les cellules de mouton, et du retard d'apparition des lésions.

Si la concentration cellulaire est assez forte au départ, il est difficile de distinguer à l'état frais les lésions cytopathogènes en raison de l'enchevêtrement des cellules. L'aspect le plus frappant de l'effet cytopathogène réside dans les inclusions nucléaires, qui s'observent dans la quasi-totalité des cellules, qu'elles soient mono ou polynucléées: Il est difficile de rapprocher cet effet cytopathogène de tout autre produit par un virus difrérent.

\# semble que le maintien à $40^{\circ}$ des cultures conserve au virus sa faculté de produire des inclusions, alors qu'à $37^{\circ}$ on assiste à la diminution de leur fréquence et de leur taille. 
La teneur en unités infectantes du milieu de culture est inférieure d'un log. à base 10 environ à celle enregistrée avec le virus PB. Cependant, si le maximum est moins élevé et atteint plus tardivement, le titre du virus se maintient pendant plus longtemps à une valeur relativement forte.

On peut rapprocher ceci de ce que l'effet cytopathogène du virus PPR est plus ménagé que celui du virus $\mathrm{PB}$, et de ce qu'il n'y a pas destruction totale des cellules atteintes par le virus. Au contraire, l'observation de flacons de culture conservés 35 jours montre que, si les cellules infectées occupent du $10^{\mathrm{e}}$ au $20^{\mathrm{e}}$ jour après la mise en culture la quasi-totalité de la surface, il se produit ensuite une sorte de «cicatrisation» par prolifération de cellules de type fibroblastiques restées saines, qui réoccupent une part importante de la paroi de verre.

Cependant, on peut conclure à une diminution de la faculté des cellules géantes à produire du virus puisqu'au $35 \mathrm{e}$ jour après la mise en culture, le titre en virus est de 10,4 seulement, bien que le tapis cellulaire soit encore constitué pour une bonne part de cellules infectées.

Le maintien à $40^{\circ} \mathrm{C}$ des cultures de virus PPR semble avoir exalté le pouvoir pathogène du virus, puisque si les 2 boucs inoculés avec le milieu de l'isolement du virus à $370 \mathrm{C}$ ont survécu, après, il est vrai; une très forte réaction, ceux inoculés avec le virus du 4 e passage à $40^{\circ} \mathrm{C}$ succombent régulièrement.

1 est vraisemblable que la température de culture élevée sélectionne les mutants virulents, comme cela a été observé pour d'autres virus. La possibilité de multiplication à température élevée est d'ailleurs considérée comme caractéristique des souches virulentes (marqueur Thêta).

Malgré cela, le, pouvoir pathogène du virus cultivé à $40^{\circ} \mathrm{C}$ reste faible pour le bœuf, et les bovins N'Dama n'ont montré qu'une faible réaction thermique après inoculation.

lis ont parfaitement résisté à l'épreuve, et leur sćrum 14 jours apròs inoculation ronformait des anticorps neutralisant le virus bovipestique à une dilution appréciable. Cependant la présence d'anticorps neutralisants n'est pas indispensable à l'état d'immunité puisque les bovins ayant reçu de faibles doses de virus se révèlent immunisés, bien que leurs sérums en soient dépourvus. Un délai de 15 jours ne suffit peut-être pas à leur élaboration à un taux décelable.

Ainsi se trouve une fois de plus confirmée la parenté antigénique entre les deux virus. Toutes les recherchcs sérologiquas ont ćtć cffcctuées par neutralisations croisées, c'est-à-dire que: le virus bovipestique de culture a été utilisé pour la recherche des anticorps induits por le virus PPR dans les sérums des boucs et des veaux inoculés, et que le sérum antibovipcstique a été employé pour l'identification du virus PPR.

II reste maintenant à comparer les titres des sérums vis-à-vis des virus homologues et hétérologues.

Le comportement particulier du virus PPR en cultures cellulaires apporte un élément nouveau permettant de considérer cette affection comme une entité nosologique distincte de la peste bovine, bien qu'étroitement apparentée.

II est permis, 'à notre sens, de considérer le virus PPR comme un virus bovipestique spontanément adapté aux petits ruminants et se perpétuant désormais chez ces espèces, indépendamment de l'espèce bovine. II diffère donc des souches bovipestiques pouvant accidentellement contaminer les ovins ou caprins telle celle étudiée par JOHNSON, (4) qui, pathogène pour deux espèces, affectait à la fois bovins ef ovins.

Le virus PPR ne peut non plus être confondu avec certains virus bovipestiques adaptés en laboratoire à l'espèce caprine, ef qui, par la suite se sont révélés spontanément transmissibles au sein de cette espèce. Ces faits, ont d'ailleurs été rapportés en Asie, mais non en Afrique. D'autre parl, le comportement chez les caprins des virus bovipestiques artificiellement adaptés est tout a fait différent de celui, du virus PPR. Seul ce dernier reproduit le tablecu clinique de la peste bovine, alors que les virus vaccins bovipestiques caprinisés ne provoquent aucune lésion visible chez les caprins infectés. L'existence de PPR a d'ailleurs été reconnue antérieurement à l'introduction en Afrique occidentale de virus vaccins caprinisés.

Enfin, il n'a pas été jusqu'ici possible de cultiver sur cellules le virus bovipestique caprinisé (PLOWRIGHT et FERRIS, 5).

Des études entreprises, peut résulter l'obtention d'un vaccin efficace contre la peste des petits ruminants, ef la peste bovine. Des expé- 
riences complémentaires seront cependant nécessaires pour confirmer l'impossibilité de contamination des ovins et caprins par les bovins inoculés de PPR.

\section{CONCLUSIONS}

10 Une souche de virus PPR a été adaptée à la multiplication en cultures de cellules de rein d'embryon de mouton.

20 Le virus provoque la formation au sein des cultures infectées de cellules multinucléées de grande taille. Dans la quasi-totalité des noyaux des cellules, apparaissent des inclusions éosinophiles de grande taille.

3o Le virus maintenu en cultures à $400 \mathrm{C} \mathrm{immu-}$ nise les bovins contre la peste bovine et conserve son pouvoir pathogène pour les caprins.

40 Le virus maintenu en cultures à 370 perd rapidement son pouvoir pathogène pour les caprins et les immunise contre le virus PPR virulent.

\section{SUMMARY}

Adaptation of the virus of « rinderpest of small ruminants 》 to tissue culture

1. - A strain of the virus of PPR (peste des petits ruminants) has been adapted to culture on embryo ovine kidney cells on which it multiplies.

2. - The virus induces the formation in the infected tissue cultures of multinuclear cells of large size. In a fair proportion of the nuclei of the cells, there appear eosinophile inclusions of large size.

3. - This tissue culture virus maintained at $40^{\circ} \mathrm{C}$ immunizises cattle against rinderpest and retains its pathogenicity for goats.

4. - Tissue culture virus maintained at $37 \circ \mathrm{C}$ rapidly loses its pathogenicity for goats and immunizises this species against virulent «PPR » virus.

\section{RESUMEN}

\section{Adaptación del virus de la peste de los rumiantes menores al cultivo celular}

1. - Una estirpe de virus PPR ha sido adaptada a la multiplicación en cultivo de células de riñón de embrión de cordero.

2. - El virus provoca la formación en el seno de los cultivos infectados células multinucleadas de gran tamaño. En la mayor parte de los nucleos de las células aparecen inclusiones eosinófilás de gran tamaño.

3. - El virus mantenido en cultivos a $40^{\circ} \mathrm{C}$ inmuniza a los bovinos contra la peste bovina y conserva su poder patógeno por lo que respecta a los caprinos.

4. - El virus mantenido en cultivos a $37^{\circ} \mathrm{C}$ pierde rápidamente su poder patógeno por lo que respecta a los caprinos y les inmuniza contra el virus PPR virulento.

\section{BIBLIOGRAPHIE}

1. MORNET (P.), ORUE (J.), GILBERT (Y.), THIERY (G.) et SOW MAMADOU. - La peste des petits ruminants en Afrique Occidentale
Française. Ses rapports avec la peste bovine. Rev. Elev. Méd. vét. Pays trop. 1956, $9: 313$ (Avec rappel de la bibliographie antérieure). 


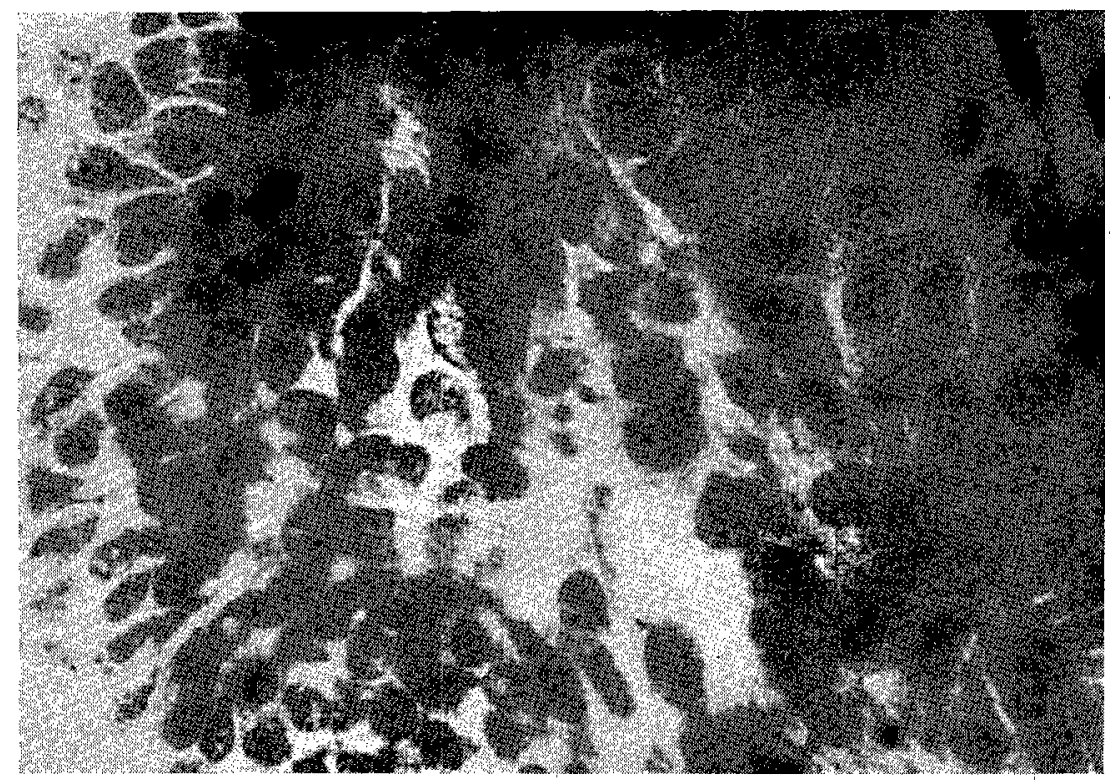

Photo no 1. - Culture de cellules épithéliales de rein d'embryon de mouton $-8 \mathrm{e}$ jour $-\times 130$.

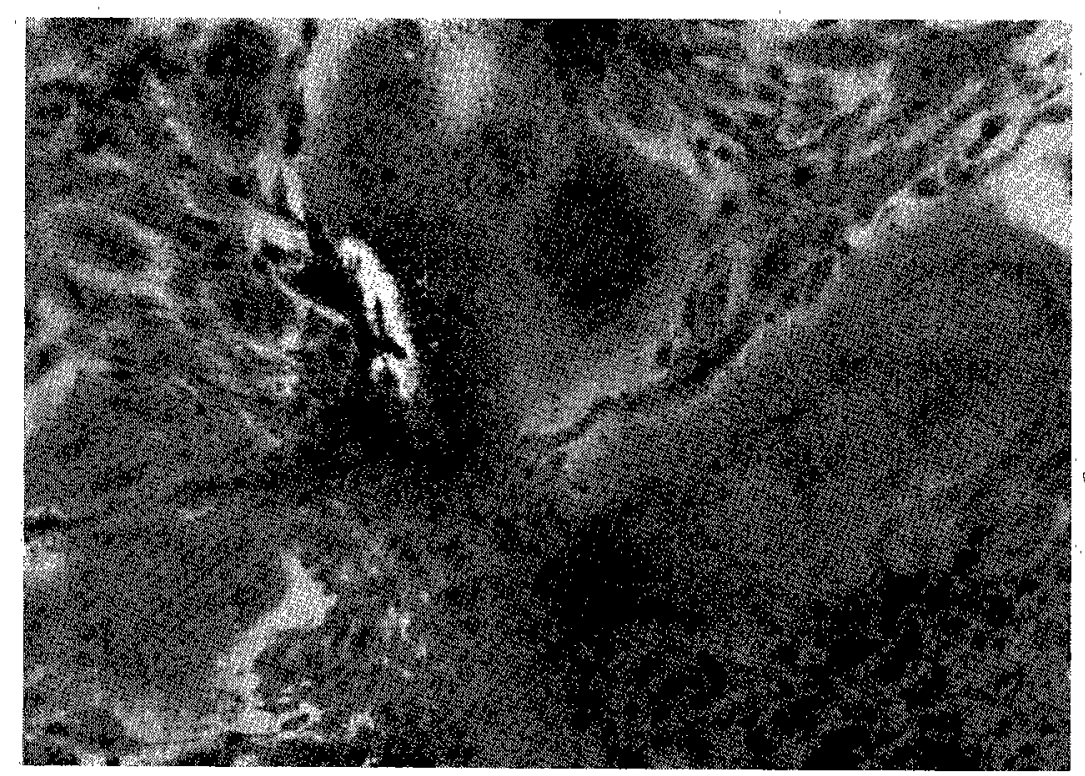

Photo no 2. - Culture de cellules épithéliales de rein d'embryon de mouton infectées par le virus P. P. R. - $4^{\mathrm{e}}$ passage, incubation à $40^{\circ} \mathrm{C}$, $8^{e}$ jour, $\times 125$ - Cellules géantes, inclusions intranucléaires. 


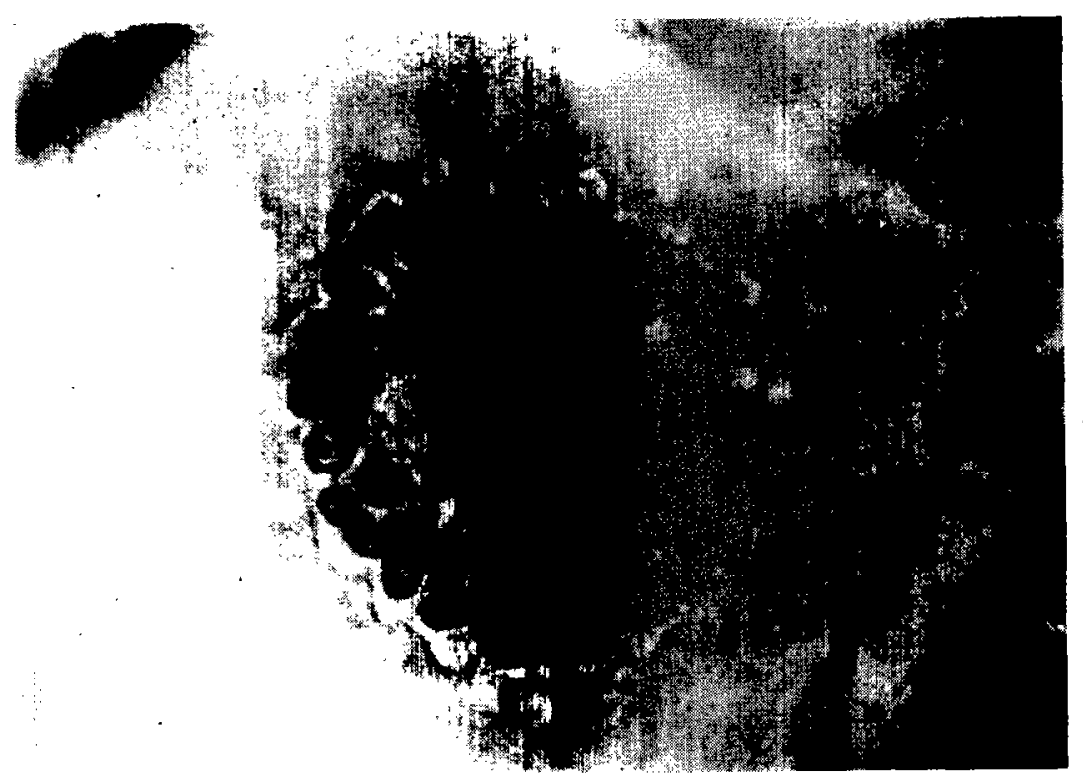

Photo no 3. - Même culture que celle représentée sur la photo $n^{\circ} 2 \times 560$. Détail d'un syncytium, inclusions intranuclécires.

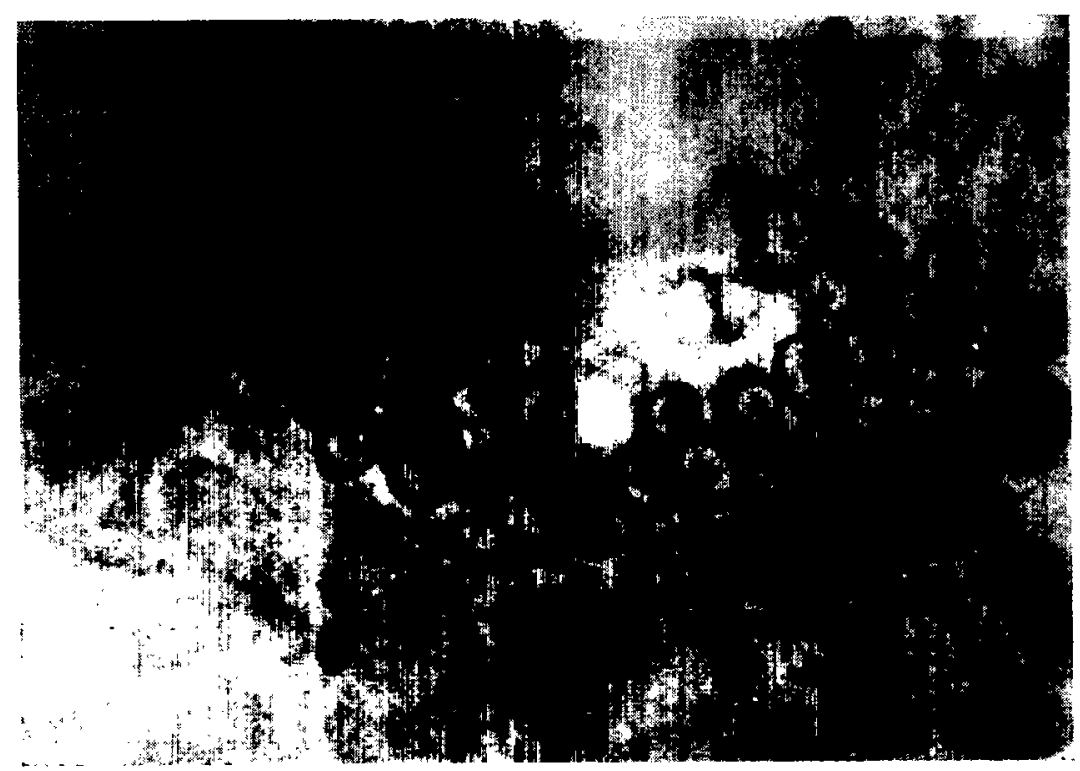

Photo no 4. - Même culture que celle représentée sur les photos no 2 et $3 \times 750$. Cellule multinucléée, inclusions intranucléaires. 


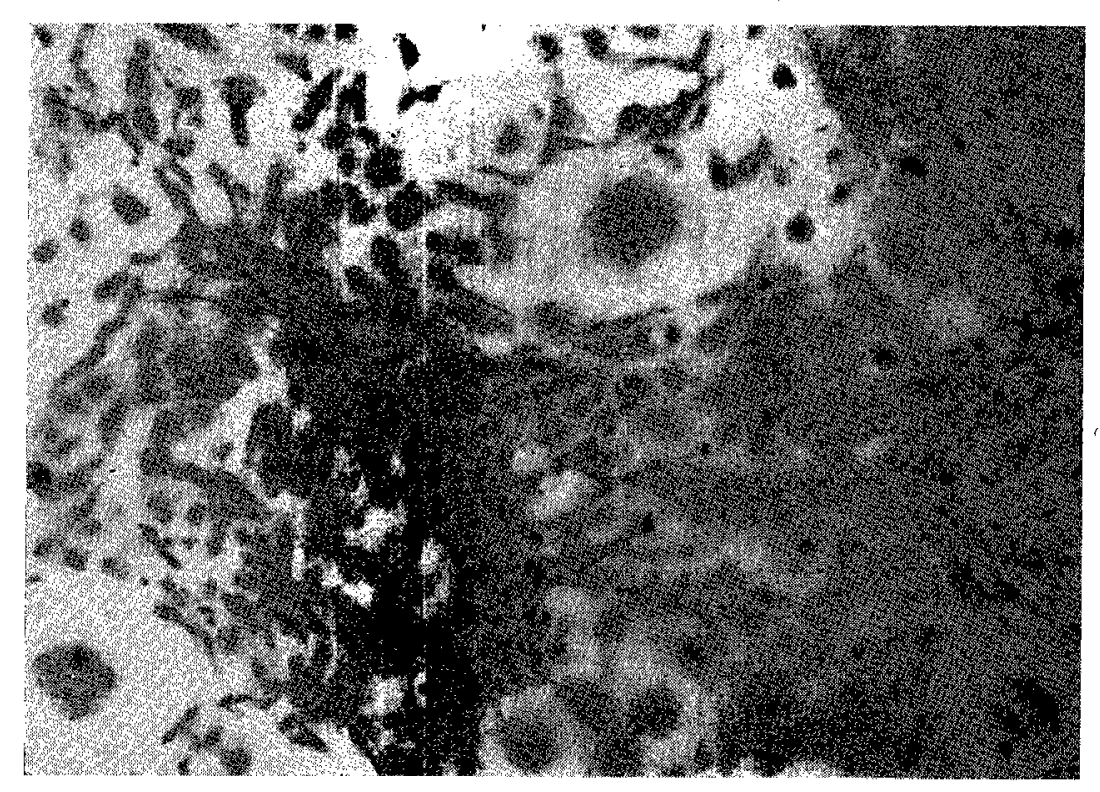

Photo no 5. - Culture de cellules épithéliales de rein d'embryon de mouton infectées par le virus P.P. R. - 11e passage, incubation $37^{\circ} \mathrm{C}, 9^{\circ}$ jour, $\times 1.25$ Aspect. de la culture, cellules multinucléées.

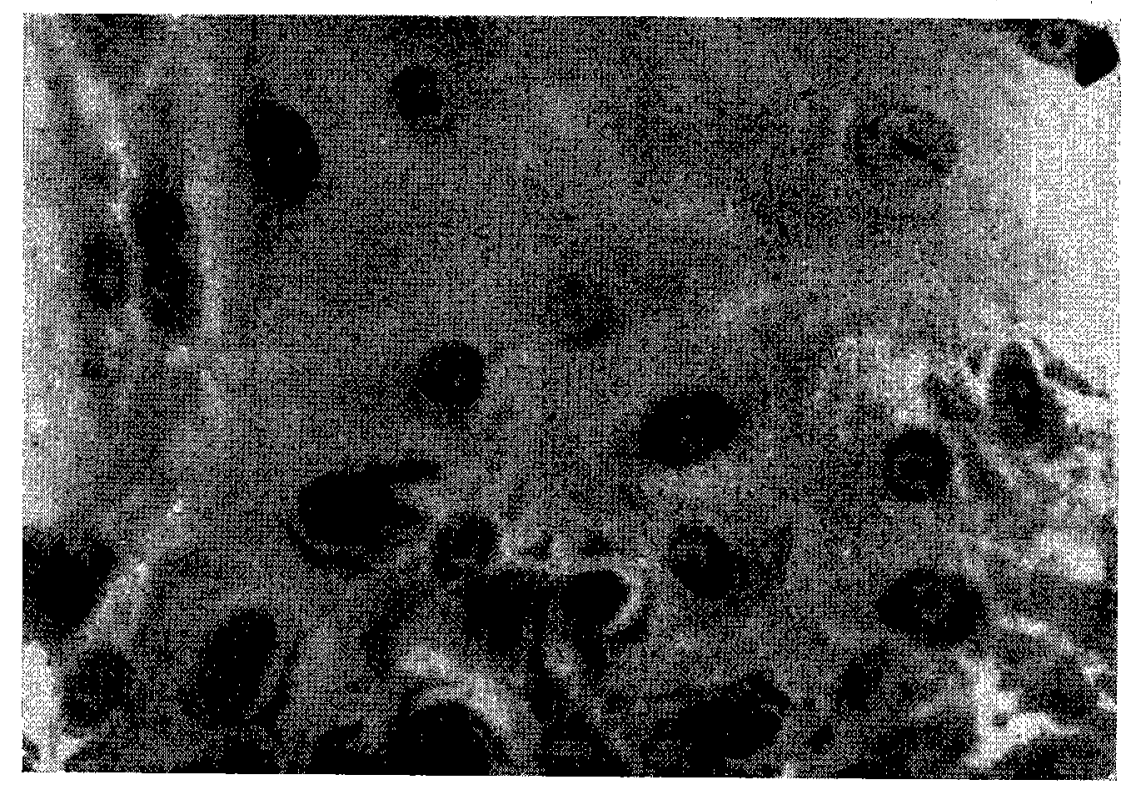

Photo $n^{0}$ 6. - Même culture que celle représentée sur la photo $n^{0} 5, \times 750$. Inclusions intranucléaires dans des cellules non groupées en syncitiums. 
2. PLOWRIGHT (W.) et FERRIS (R. D.). Studies with rinderpest virus in tissue culture. I. growth and cytopathogénicity. J. comp. Path. 1959, $69: 152$.

3. GILBERT (Y.) et MONNIER (J.). - Adaptation d'une souche de virus bovipestique à la culture cellulaire. Rev. Elev. Méd. vét. Pays trop. 1962, 15: 4.
4. JOHNSON (R. H.). - An outbreak of rinder pest involving cattle and sheep. Vét. Rec. 1958, $70: 457$.

5. PLOWRIGHT(W.) et FERRIS (R. D.). - Studies with rinderpest virus in tissue culture. A technique for the détection and titration of virulent virus in cattle tissues. Rés. Vét. Sci. 1962, 3 : 94. 